\title{
A SOCIOLOGIA COMO PROFISSÃO PÚBLICA NO BRASIL'
}

\author{
Simon Schwartiman ${ }^{*}$
}

\begin{abstract}
É notável como, nas últimas décadas, a sociologia brasileira cresceu e se desenvolveu, adquirindo muitas das características de uma profissão. Duas indagações, no entanto, decorrem desse processo. A primeira é a natureza dessa profissionalização - se ela se aproxima do modelo tradicional das "profissões cultas", como a medicina ou direito, ou se aproxima mais daquilo que se denomina hoje de "profissão acadêmica". A segunda é em que medida, nesse processo de profissionalização, a sociologia teria ou não perdido seu papel de "profissão pública", e os sociólogos, seu papel intelectual. Isso leva a uma terceira questão, que é a da pertinência ou não de se esperar que a sociologia tenha e mantenha essa característica de profissão pública.

PALAVRAS-CHAVE: sociologia pública, sociologia brasileira, sociologia crítica, sociólogos, profissões.
\end{abstract}

\section{DE MARX A FOUCAULT}

Quantos de nós começamos nossas carreiras inspirados nessa tese, mesmo antes de saber sua origem? O projeto intelectual e político do jovem Marx, escrito na flor de seus 27 anos, não poderia ser mais ambicioso. Em termos atuais, ele propunha:

- Uma filosofia abrangente, que incluía a história, a economia e a sociologia, além da própria filosofia, que seria baseada no conhecimento material - científico e empírico - da realidade.

- Uma teoria de agência, segundo a qual a realidade não era externa e alheia às pessoas, a ser conhecida de forma abstrata, mas o resultado das práticas coletivas e concretas de transformação social.

- Uma narrativa da história, explicitada poucos anos depois no Manifesto Comunista de 1848,

* Sociólogo e Ph.D. Ciências Políticas pela Universidade da Califórnia, Berkeley. Presidente do Instituto de Estudos do Trabalho e Sociedade (IETS) no Rio de Janeiro. Praia do Flamengo 100, Cobertura. Cep: 22210-030 - Rio de Janeiro - Brasil.simon@schwartzman.org.br; simon@iets.org.br

${ }^{1}$ Conferência apresentada no $14^{\circ}$ Congresso Brasileiro de Sociologia, Rio de Janeiro, 31 de Julho de 2009.
S filósofos têm apenas interpretado o mundo de maneiras diferentes; a questão, porém, é transformá-lo. K. Marx, $11^{\text {a }}$ Tese sobre Feuerbach, em A Ideologia Alemã, 1845.

que abraçava as conquistas da modernidade, ao mesmo tempo em que a criticava.

- Uma perspectiva critica sobre a religião, o estado, a economia, a sociedade civil e as instituições, que desmascarava suas alienações atuais e apontava o caminho para sua superação futura. - Uma ética de compromisso pessoal e engajamento em favor dos oprimidos, que fazia do filósofo um homem prático, envolvido e participante dos processos políticos de transformação da sociedade.

- Uma perspectiva critica e reflexiva sobre o próprio conhecimento, que deveria ser validado e interpretado a partir da inserção prática do "filósofo" na vida social.

O que aconteceu com esse projeto desde então?

Primeiro, a antiga filosofia se fragmentou. A economia, a ciência política, a antropologia e a própria filosofia se desenvolveram como correntes intelectuais e disciplinas acadêmicas separadas, todas elas pretendendo, de alguma maneira, levar à frente o antigo ideal de, ao mesmo tempo, interpretar e transformar o mundo, mas cada qual à 
sua maneira, e sem incorporar devidamente os conhecimentos e avanços das demais. Qual o espaço e o lugar da sociologia nesse mundo fragmentado das diversas ciências sociais?

Depois, a grande narrativa de modernidade e progresso - que Marx e Engels haviam herdado de Hegel e combinado com o evolucionismo do século 19 - perdeu força e credibilidade. Não se trata somente de que ela tenha se modificado-podemos interpretar a obra de sociólogos clássicos como Weber e Durkheim como tentativas de retomar, aprofundar e atualizar essas narrativas. Com o fim do "socialismo real", no entanto, e o surgimento do pós-modernismo, são as próprias ideias de valores associados à evolução e ao progresso que entram em crise. O que fica em seu lugar?

O pós-modernismo transformou a filosofia crítica, que tinha um forte componente de transformação, no que hoje, muitas vezes, se chama de “desconstrução”, postura geralmente associada a um profundo pessimismo sobre a sociedade e o mundo contemporâneo, na interpretação de autores como Walter Benjamin e Michel Foucault, e da Escola de Frankfurt de maneira geral. Não se trata mais, como para Marx, de criticar o presente para construir o futuro, mas, quase que exclusivamente, para lamentá-lo.

Finalmente, a sociologia se profissionalizou como disciplina universitária, e a atuação do cientista social como intelectual orgânico, na fórmula proposta por Antonio Gramsci e simbolizada pela atuação política de Jean-Paul Sartre até os anos 1960, perdeu muito de sua credibilidade, sobretudo, novamente, após o fim do “socialismo real”. Que papéis sociais ainda cabem ao sociólogo, espremido entre a ciência política e a economia, sujeito às regras de carreira das universidades, e sem um instrumental técnico e profissional que o permita atuar como um profissional "normal”, à maneira dos advogados, contadores e administradores?

O resultado de todas essas transformações foi que o fundamento moral da ação intelectual e profissional do cientista social, antes baseado no engajamento político em favor de um projeto claro de transformação social, também se fragmentou e diversificou. Para muitos dos que continuam na militância política e social, a ética dos direitos individuais, subjetivos e imediatos toma o lugar dos projetos globais e de longo prazo de transformação, e os interesses dos grupos e movimentos em que participam passam a ser interpretados como se fossem de interesse geral. Para outros, sobretudo nas universidades, prevalecem os valores da produção científica e intelectual, medida de forma empobrecida pelos indicadores convencionais de desempenho acadêmico; para os poucos que se dedicam ao trabalho profissional para clientes públicos e privados, são os valores do sucesso profissional, expresso nas carreiras em empresas e organizações, assim como nas recompensas salariais, que adquirem primeiro plano. E existem ainda os que escrevem e se comunicam com o grande público, através de jornais e livros de cunho geral, e que valorizam, sobretudo, o papel que possam ter como formadores de opinião.

\section{O CREPÚSCULO DA SOCIOLOGIA?}

Essas transformações e a fragmentação da antiga filosofia nas atuais ciências sociais podem ser vistas tanto como enriquecimento quanto como perda, ou, mais simplesmente, como uma nova realidade que devemos enfrentar. Um exemplo da visão otimista foi dado por Tom Dwyer, em seu discurso de posse como presidente da Sociedade Brasileira de Sociologia (SBS), em 2007:

Teremos que eleger prioridades dentre as quais gostaria de destacar algumas: garantir que a reintrodução da Sociologia no ensino médio seja feita com qualidade e de modo a fortalecer a disciplina; reforçar a capacidade da Sociologia brasileira de refletir de maneira rigorosa sobre as transformações no país; contribuir a manter a disciplina aberta à variedade de objetos e de abordagens teóricas e epistemológicas sem levar à excessiva fragmentação; garantir o espaço das ciências sociais dentro de um cenário marcado pela tendência de crescente padronização da mensuração da produtividade científica; e internacionalizar não apenas o foco, mas também o alcance da nossa sociologia.

Não há nada a questionar, muito pelo contrário, em relação a essa agenda de incorporação das 
diferentes facetas e desafios que a sociologia enfrenta hoje no Brasil-é isto exatamente o que se espera do presidente de uma associação profissional. É possível focalizar a atenção, no entanto, nas dificuldades com que a sociologia se confronta, o que foi feito por José Joaquín Brunner em 1997, por ocasião dos 40 anos da Faculdade Latino-americana de Ciências Sociais (FLACSO), em Santiago do Chile. Para Brunner, a sociologia precisa completar o luto de duas grandes perdas, a da grande narrativa da modernidade e a do desenvolvimento das ciências sociais como "Big Science" (Price 1969), concentrada em grandes instituições como o Banco Mundial, que trabalham com grandes equipes e metodologias mais típicas de disciplinas como a economia, a demografia e a estatística do que da sociologia convencional. Para descrever o que ocorre, Brunner usa a metáfora das tradições e estilos literários:

Si uno piensa en el desarrollo de la sociología clásica, por ejemplo, verá que ella es algo así como la épica del surgimiento de la modernidad. $\mathrm{Su}$ referencia, igual que en la epopeya, es el mundo de los comienzos, de las rupturas originantes; describe una suerte de periplo desde el pasado. Tal es el paso de la comunidad a la sociedad de Tonnies; o de la solidaridad moral a la orgánica, de Durkheim; o de la costumbre a la convención; o de las agrupaciones sin clases ni dominación a la historia de las civilizaciones; en suma, las "imágenes de corte" de nuestra disciplina. Sólo a partir de ellas se vuelve posible, posteriormente, entender los procesos - en cierto nivel casi-míticos - de la racionalización, la secularización, la universalización, la diferenciación o la modernización; para no hablar de conceptos más descriptivos como urbanización e industrialización. Los propios autores clásicos de la sociología son "teóricos épicos", como los llama un autor; en el sentido de que sus obras representan un esfuerzo heroico de comprensión, cuyo producto es una sabiduría con la cual podemos conversar hasta hoy. (Brunner, 1997)

No entanto, essa grande tradição já não teria muito a nos dizer no mundo da pós-modernidade e da pós-história, e a nova sociologia, dedicada ao microscópico e ao qualitativo, não teria conseguido ocupar o seu lugar:

La gran sociología habla bien de hombres muertos; los actores del pasado: el Estado, los partidos, las clases sociales, los sindicatos, las iglesias oficiales, las grandes religiones, las civilizaciones, las revoluciones. En cambio, prácticamente no se refiere a hombres vivos: los enfermos de SIDA, soldados, empleados del Registro Civil, obreros de Lota, ídolos de la canción, innovadores, académicos, pobres de hoy, nuevos ricos, enamorados, resentidos, jugadores de fútbol, atormentados por la sequía, emergentes grupos de poder. Por su parte, las sociologías dramáticas y situacionistas hablan mal o poco de los muertos - de las guerras o las epidemias, por ejemplo - y, entre los vivos que son su especialidad, elige preferentemente a quienes se hallan de alguna forma excluidos de la corriente principal de la modernidad.

Em resumo, conclui Brunner, a sociologia teria perdido seu espaço, devendo abrir caminho, agora, para outras narrativas:

Ni sus grandes categorías sistémicas, ni sus pequeños conceptos de interpretación de la vida cotidiana, parecen sostenerse en pie frente al doble embate del Banco Mundial y la novela contemporánea. Aquel describe y analiza más fehacientemente los sistemas y proporciona además manuales para actuar sobre ellos. Y ésta representa más ricamente que la sociología los elementos de la vida interior y colectiva. De hecho, uno debería preguntarse si acaso no sería preferible, antes que partir enseñando a los autores clásicos y contemporáneos de la disciplina, leer las novelas de Joyce, Durrel, Vargas Llosa, Becket, Julián Barnes, Aguilar Camín o Mafud.

\section{[...]}

La sociología se halla particularmente mal dotada para las preguntas pos-modernas, las cuales tienen que ver, al final, con puntos de vista cambiantes, con el "pensamiento débil", con fragmentos, con dilemas de orden moral, con historias e historietas y no con "la" Historia. Por su origen epopeico y su insalvable sesgo épico, el sistema ideológico y de lenguaje de nuestra disciplina se queda paralizado ante la falta de seriedad de lo contemporáneo; ante los juegos del poder; ante la ironía propia de todo lo descentrado, pluralista y diverso que hay en nuestra época y conciencias, A la sociología no le viene bien un mundo en que predominan los estilos de vida, las formas de consumo y no de producción, los travestismos y las parodias, y donde se perciben con tal claridad las irracionalidades de la historia. No le viene bien una época sin tradiciones, que duda de si misma y del progreso y que se burla de las estructuras y los valores, de lo sagrado y la memoria, para dedicarse a los intercambios y el cinismo conceptual, al cultivo personal y las creencias esotéricas.

A aparente preferência de Brunner pela novela pode ser interpretada em dois sentidos. $\mathrm{O}$ primeiro, com o qual me identifico, é a busca de uma sociologia menos preconcebida, menos pre- 
tensiosa, mais aberta à riqueza, à multiplicidade e ao inesperado da vida social. O segundo, que ele certamente não pratica, seria a substituição do modo sociológico de trabalho, dentro dos cânones usuais da observação sistemática, comprovação de hipóteses e refutações, pela produção literária e os métodos típicos da análise textual. O bom escritor tem, em relação ao sociólogo, a vantagem de poder dar asas à imaginação e usar os sentimentos e a intuição própria e dos seus leitores como prova de suas verdades, e, além disso, domina a arte de escrever. Mas a verdade intuída de um pode ser a falsidade do outro, e poucos sociólogos estariam dispostos a abandonar a ambição do conhecimento comprovável e verificável pela inspiração literária.

\section{OS MODOS DE TRABALHO E O OBJETO DA SOCIOLOGIA}

Na $10^{\mathrm{a}}$ Tese sobre Feuerbach Marx diz que “o ponto de partida do materialismo antigo é a sociedade civil; o do materialismo moderno, a sociedade humana ou a humanidade social.” É possível interpretar essa frase como se ela pretendesse contrastar a sociedade formada por indivíduos isolados e a humanidade em seu sentido mais pleno, que inclui desde os modos de produção até as estruturas políticas de dominação. Se isso é assim, poderíamos interpretar a tese de que o campo de trabalho do sociólogo é a sociedade civil, defendida por alguns sociólogos hoje, como uma volta a Feuerbach.

É o que faz o sociólogo marxista Michael Burawoy, em um famoso discurso como presidente da American Sociological Association (ASA), em 2004, que gerou uma grande polêmica que ainda perdura (Burawoy, 2007a). Imitando Marx, Burawoy propõe também onze teses em favor do que ele denomina “sociologia pública”, e a $11^{a}$ é também a mais famosa e contenciosa:

Se o ponto de partida da economia é o mercado e seus prolongamentos, e o da ciência política é o estado e a garantia da estabilidade política, então o ponto de partida da sociologia é a sociedade civil e a defesa do social. Em tempos da tirania do mercado e do despotismo do estado, a sociologia - e em particular seu lado público - defende os interesses da humanidade (2007a, p. 55) (tradução do autor).

Burawoy propõe quatro tipos diferentes de sociologia, que, segundo ele, poderiam e deveriam coexistir. A primeira seria a "sociologia profissional”, que ele define como a sociologia acadêmica, organizada como uma ciência empírica convencional, que existe e se desenvolve nos departamentos de sociologia das universidades. A segunda, também acadêmica, é o que ele denomina de "sociologia crítica”, preocupada com os debates e discussões sobre a natureza da sociologia, como por exemplo, esta minha apresentação. As outras duas seriam extra-acadêmicas, de duas modalidades. A terceira seria a sociologia aplicada, orientada para a implementação de políticas públicas, a "sociologia para políticas públicas”, trabalhando para clientes, preocupada com resultados práticos e efetivos. A quarta, finalmente, seria a "sociologia pública”, em que o sociólogo participa e se envolve em redes que vão além do mundo acadêmico, ajudando a criar públicos com os quais se comunica e que atestam a relevância de suas contribuições. Tanto a sociologia profissional quanto a aplicada seriam “instrumentais", enquanto que a sociologia crítica e pública seriam críticas.

Embora Burawoy afirme que os quatro tipos de sociologia devem e podem coexistir, não há dúvida que ele vê a sociologia aplicada como menos digna, e a sociologia pública como a mais importante. Para ele, a sociologia estaria passando por uma terceira fase, que teria deixado para trás o tempo em que se pensava, como Karl Polanyi, que os mercados e a política poderiam ser domesticados pela sociedade (Polanyi, 2001). O objeto da sociologia hoje, afirma, não pode ser mais a construção do estado nacional e da coesão social, como na primeira fase, nem os direitos sociais, da segunda; o espaço que lhe sobra é o dos direitos humanos. O sociólogo público dessa terceira fase é o militante das organizações e movimentos sociais, por fora, independentemente e contra os mecanismos opressivos do Estado e do Mercado. 
Segundo ele:

Nesta era da terceira onda de marquetização, a sociologia se volta para a sociedade civil, acima e abaixo do estado nacional. Abaixo do estado nacional os sociólogos forjam uma sociologia pública com comunidades locais e até mesmo uma sociologia aplicada associada aos governos locais que devem arcar com o peso do apoio social aos cidadãos, responsabilidade que o estado federal abdicou. Acima do estado, a sociologia pública se desenvolve em forte associação com associações, organizações e movimentos transnacionais. A terceira onda de marquetização exige uma sociologia pública que conecta os públicos locais em uma formação global (Burawoy, 2007b, p. 325) (tradução do autor) .

Seria impossível reproduzir aqui as grandes discussões e criticas que tais ideias suscitaram. No ambiente acadêmico norte-americano, onde os sociólogos geralmente vivem encapsulados em seus departamentos universitários, congressos e revistas especializadas, sentindo a ameaça crescente do imperialismo acadêmico dos economistas, que invadem sem cerimônia os campos tradicionais das outras disciplinas (Lazear, 2000), a proposta de uma forte sociologia pública associada aos movimentos sociais, feita justamente pelo presidente da ASA, não poderia deixar de repercutir. Algumas das críticas foram de que o conceito de intelectual público, ou orgânico (termo emprestado diretamente de Gramsci), proposto por Burawoy, é parcial e sectário, porque associado a uma interpretação extremada da história recente e à demonização do Estado e do mercado; que a "sociedade civil" não é, necessariamente, o espaço da virtude; e de que a subordinação da sociologia científica e acadêmica aos critérios da militância política corre o risco de politizar o campo intelectual da sociologia, cuja força estaria, em última análise, na qualidade da produção científica e na independência intelectual de seus participantes (Brint 2007; McLaughlin; Kowalchuk; Turcotte, 2007; Patterson, 2007; Stinchcombe, 2007; Touraine, 2007).

Na Europa e na América Latina, onde a sociologia profissional acadêmica está menos institucionalizada, e onde os sociólogos normalmente dialogam com a sociedade, escrevem em jornais, publicam livros para o grande público e se envolvem com os grandes temas de políticas públicas, a proposta soa muito menos revolucionária, e a visão extrema da sociedade civil como o último baluarte da humanidade contra a opressão dos mercados e do Estado não faz muito sentido.

Em que medida a sociologia, no Brasil, está se aproximando ou se afastando desses diferentes modos de trabalho, e que consequências podemos esperar dessa evolução?

\section{A PROFISSIONALIZAÇÃO DA SOCIOLOGIA NOBRASIL}

A grandiosidade do $14^{\circ}$ Congresso Brasileiro de Sociologia, com centenas de participantes e mais de trinta grupos de trabalho das mais diversas especialidades, mostrou o quanto a sociologia brasileira cresceu desde a fundação da Sociedade Brasileira de Sociologia - SBS 60 anos atrás, quando todos os sociólogos do país mal cabiam dentro de um fusca. Hoje, só a SBS tem oitocentos e dezessete associados. Segundo a CAPES, o Brasil possui quarenta e cinco cursos de pós-graduação em sociologia, trinta dos quais outorgando títulos de doutorado, com novecentos e dezenove professores, e formando quase trezentos doutores por ano ("sociologia" aqui inclui os programas de ciências sociais, mas exclui os de disciplinas irmãs, como a ciência política). A pós-graduação em sociologia não é muito diferente, em suas dimensões, das de outras áreas como o direito, a administração, a economia e a educação.

As coisas são muito diferentes, no entanto, no nível de graduação, onde o número de estudantes de ciências sociais é reduzido, se comparado ao de áreas como administração e direito, com mais de seiscentos mil estudantes matriculados; educação, com quase trezentos mil; e economia, com mais de cinquenta mil. Juntas, as ciências sociais e a ciência política não matriculam mais do que trinta e cinco mil estudantes ao ano, e graduam cerca de seis mil. Dividindo o numero de formados na graduação pelo de matriculados em mestrados nas diferentes áreas, podemos estimar 
Tabela 1 - Cursos de pós-graduação em Ciências Sociais

\begin{tabular}{l|c|c|c|c|c|c|c}
\hline & Sociologia & $\begin{array}{c}\text { Ciência } \\
\text { Política }\end{array}$ & $\begin{array}{c}\text { Antropo } \\
\text { logia }\end{array}$ & Direito & $\begin{array}{c}\text { Adminis- } \\
\text { tração }\end{array}$ & Economia & Educação \\
\hline Cursos de mestrado & 41 & 21 & 16 & 62 & 42 & 18 & 47 \\
\hline Mestrados profissionais & 2 & 1 & 1 & 0 & 23 & 12 & 0 \\
\hline Cursos de doutorado & 27 & 11 & 10 & 22 & 25 & 18 & 30 \\
\hline Professores de pós-graduação & 919 & 342 & 289 & 1.431 & 1.584 & 745 & 2.199 \\
\hline Alunos de mestrado & 1.355 & 485 & 394 & 4.293 & 3.010 & 1.098 & 5.757 \\
\hline Titulados mestrado & 510 & 167 & 360 & 1.001 & 692 & 573 & 2.862 \\
\hline Alunos de doutorado & 1.369 & 353 & 148 & 1.685 & 1.246 & 406 & 2.482 \\
\hline Titulados doutorado & 266 & 53 & 55 & 253 & 134 & 110 & 659 \\
\hline
\end{tabular}

Fonte: Portal da CAPES

que aproximadamente um em cada dois formados em sociologia busca fazer pós-graduação, comparando com um em cada dezenove em direito, ou um em cada seis em economia.

Esse dado mostra a debilidade do título profissional do sociólogo no nível de graduação. No Brasil, ainda é o titulo de graduação que capacita para o exercício legal das profissões, e tem havido um esforço, ao longo dos anos, de estruturar a profissão do sociólogo dessa forma. Temos uma Federação Nacional que congrega sindicatos de sociólogos de vários Estados, dos quais o mais importante é o de São Paulo, Esses sindicatos têm militado a favor da criação de Conselhos Federal e Regionais de Sociologia, aos quais os sociólogos diplomados pudessem se filiar, e que pudessem fazer cumprir o que diz o artigo $3^{\circ}$ do Decreto de regulamentação da profissão de 1984, segundo o qual

Tabela 2 - Cursos de graduação presencial em Ciências Sociais, Negócios e Direito

\begin{tabular}{l|c|c}
\hline & Matrículas & Concluintes \\
\hline Ciências Sociais, Negócios e Direito (total) & 2.050 .282 & 301.173 \\
\hline Administração & 680.687 & 93.978 \\
\hline Direito & 613.950 & 82.830 \\
\hline Economia & 52.631 & 6.788 \\
\hline Ciências Sociais & 18.039 & 2.642 \\
\hline Cência Política e Educação Cívica & 15.294 & 2.809 \\
\hline Sociologia e Estudos Culturais & 1.482 & 186 \\
\hline Formação de professor de Sociologia & 145 & 657 \\
\hline Formação de professor de Estdos Sociais & 2.922 & 66.283 \\
\hline Educação & 284.725 & \\
\hline Fonte: Portal da CAPES & & 57 \\
\hline
\end{tabular}

os órgãos públicos da administração direta ou indireta ou as entidades privadas, quando encarregados da elaboração e execução de planos, programas e projetos socioeconômicos ao nível global, regional ou setorial, manterão, em caráter permanente, ou enquanto durar a referida atividade, sociólogos legalmente habilitados, em seu quadro de pessoal, ou em regime de contrato para a prestação de serviços. (Decreto $n^{\circ}$ 89.531, de 05 de abril de 1984)

Uma das conquistas recentes do Sindicato dos Sociólogos de São Paulo foi assinar, junto com outros sindicatos, uma convenção coletiva de trabalho com o Sindicato Nacional das Empresas de Arquitetura e Engenharia Consultiva, que, entre outras coisas, fixa um piso salarial regional para os sociólogos de R\$3.528,00 para 2008-2009. A obrigatoriedade do ensino de sociologia nas escolas de ensino médio, aprovada recentemente, é outra conquista sindical.

Não conheço dados sistemáticos sobre as atividades efetivas dos sociólogos com diplomas de graduação no Brasil, mas a pouca evidência disponível sugere que não existem muitos empregos para que sociólogos possam trabalhar "na execução de planos, programas e projetos socioeconômicos”, mesmo supondo que eles adquiram essa competência em seus cursos de graduação. E, embora a obrigatoriedade do ensino 
se sociologia nas escolas possa ampliar o mercado de trabalho para os graduados, não há muita evidência de que o magistério secundário já esteja se tornando em uma opção profissional privilegiada para os sociólogos.

Minha hipótese é de que os principais campos de trabalho para os sociólogos brasileiros, hoje, são as organizações não-governamentais da sociedade civil, o trabalho na administração pública e a carreira acadêmica. Diferentemente de Burawoy, acredito que é no mundo acadêmico, da liberdade de pesquisa e do rigor científico, que deveria estar a âncora que desse ao sociólogo a liberdade de trabalhar com autonomia e independência intelectual nos outros setores. A questão que se coloca é se essa âncora realmente funciona, ou se, ao contrário, são as agendas das organizações da sociedade civil e das burocracias públicas, assim como dos partidos e movimentos políticos que permeiam as instituições, que acabam determinando o que ocorre no âmbito da pesquisa acadêmica e profissional.

Não há dúvida de que uma sociologia aberta para o público, com temas trazidos pela sociedade e cujas conclusões são testadas e discutidas pela sociedade, é muito mais rica e interessante que uma sociologia trancafiada nos muros disciplinares e dedicada aos rituais dos jogos de poder e prestígio da academia. $\mathrm{O}$ desafio que vejo para os sociólogos no Brasil é o de estarem atentos e sintonizados com essa agenda pública e, ao mesmo tempo, consolidar uma sociologia que mantenha sua independência e sua relevância, tanto em relação aos rituais acadêmicos quanto em relação às organizações e movimentos sociais com os quais dialoga ou dos quais participa. Existem duas condições para que isso possa ser feito. A primeira é que o campo do espaço acadêmico possa se fortalecer cada vez mais, fazendo com que os valores e os benefícios do trabalho e da independência intelectual prevaleçam sobre outras motivações e interesses. O segundo é que a sociologia consiga retomar, de forma criativa e significativa, seu espaço intelectual e sua relevância para a sociedade.

Sem poder elaborar muito aqui, eu diria, em relação ao segundo ponto, que a sociologia não pre- cisa nem deve se colocar contra a política e a economia, e que a agenda da modernidade está longe de estar superada (Schwartzman, 2004). Precisamos ainda, e cada vez mais, de um estado nacional que funcione, de uma economia que produza e distribua a riqueza, e de instituições capazes de fazer a mediação entre o social, o econômico e o político, assim como entre o local e o nacional.

Nada disso é mais campo exclusivo de estudo e ação dos sociólogos. Mas existe uma forte tradição na sociologia de pensar e entender as instituições, que tanto a economia quanto a ciência política negligenciaram quando abraçaram o individualismo metodológico, e que precisa ser recuperada. A elaboração dessa visão institucional, combinada com a perspectiva histórica e a incorporação inteligente das contribuições de outras disciplinas, em textos claros e que façam sentido para os interlocutores de fora dos círculos acadêmicos, é o que melhor caracteriza, me parece, o exercício público da profissão de sociólogo.

Alain Turaine, o único europeu a participar das discussões americanas sobre a sociologia pública, assim define o seu papel:

É necessário definir a sociologia como a busca dos processos de ação, social e política, que tratam de preencher o espaço entre as situaçõ̃es e as representações. A sociologia não pode mais ser definida como o estudo da sociedade ou dos sistemas sociais em geral, mas como o estudo dos processos através dos quais os determinantes econômicos ou políticos, por um lado, e os indivíduos e grupos socialmente definidos, por outro, possam se conectar, gerando ações coletivas, processos políticos e atitudes pessoais e coletivas (Touraine 2007, p. 69).

Parece-me um bom ponto de partida.

(Recebido para publicação em julho de 2009) (Aceito em agosto de 2009)

\section{REFERÊNCIAS}

BRINT, Steven. Guide for the perplexed: on Michael Buroway's Public Sociology. In: LAWRENCE, T. Nichols. Public sociology: the contemporary debate. New Brunswick: Transaction Publishers, 2007. p. 237-262. 
BRUNNER, José Joaquín. Sobre el crepúsculo de la sociologia y el comienzo de otras narrativas. Revista de Crítica Cultural. Santiago do Chile, n. 15, nov. 1997.

BURAWOY, Michael. For public sociology. In: CLAWSON, Dan et al. Public sociology: fifteen eminent sociologist debate politics and the profession in the twenty-first century. Berkeley: University of California Press. 2007a. p. 23-65.

Third wave sociology and the end of pure science. In: LAWRENCE, T. Nichols. Public sociology: the contemporary debate. New Brunswick: Transaction Publishers. 2007b. p. 340.

LAZEAR, EP. Economic imperialism. Quarterly journal of economics, n. 115, p. 99-146. 2000.

MCLAUGHLIN, Neil; KOWALCHUK, Lisa; TURCOTTE, Kerry. Why sociology does not need to be saved: analytic reflections on public sociology. In: LAWRENCE, T. Nichols. Public sociology: the contemporary debate. New

PATTERSON, Orlando. About public sociology. In CLAWSON, Dan et al. Public sociology: fifteen eminent sociologists debate politics and the profession in the twenty-first century. Berkeley: University of California Press. 2007. p. 176-194.
POLANYI, Karl. The great transformation. Boston: Beacon Press. 2001

PRICE, Derek J de Solla. Little science, big science. New York: Columbia Univ. Press, 1969.

SCHWARTZMAN, Simon. Pobreza, exclusão social e modernidade: uma introdução ao mundo contemporâneo. São Paulo: Augurium Editora. 2004.

STINCHCOMBE, Arthur A. Speaking truth to the public, and indirectly to power. In: CLAWSON, Dan et al. Publi Sociology: fifteen eminent sociologists debate politics and the profession in the twenty-first century. Berkeley: University of California Press. 2007. p. 135-144.

TOURAINE, Alain. Public sociology and the end of society. In: In: CLAWSON, Dan et al. Public Sociology: fifteen eminent sociologists debate politics and the profession in the twenty-first century. Berkeley: University of California Press. 2007. p. 67-78. 


\section{THE SOCIOLOGY AS A PUBLIC PROFESSION IN BRAZIL}

\section{Simon Schwartzman}

It is notable how, in the last decades, Brazilian sociology grew and evolved, and aquired many of the characteristics of a profession. Two questions, however, come from this process. The first is the nature of this professionalization - if it approaches the traditional model of the "educated professions", as medicine or law, or if it approaches what is called today an "academic profession". The second one is the measure, in this professionalization process, in which sociology would have lost or not its role as a "public profession", and the sociologists, their intellectual role. And thus to a third question, that is the pertinence or not of expecting sociology to have and maintain this characteristic of public profession.

KEY WORDS: public sociology, Brazilian sociology, critical sociology, sociologists, profession.

\section{LA SOCIOLOGIE EN TANT QUE PROFESSION PUBLIQUE AU BRESIL}

\section{Simon Schwartzman}

Il est certain qu'au cours des dernières décennies la sociologie brésilienne a pris de l'ampleur, s'est développée et a acquis les caractéristiques d'une profession. Cependant deux questions découlent de ce processus. La première est de savoir quelle est la nature de cette professionnalisation - si elle se rapproche du modèle traditionnel des "professions savantes", comme la médecine ou le droit, ou si elle se rapproche plutôt de ce qu'on appelle aujourd'hui "profession académique". La deuxième est de savoir dans quelle mesure, au cours de ce processus de professionnalisation, la sociologie aurait ou non perdu son rôle de "profession publique”, et les sociologues leur rôle intellectuel. Ceci mène à une troisième question, celle de savoir s'il est pertinent ou non de s'attendre à ce que la sociologie ait et maintienne cette caractéristique de profession publique.

Mots-CLÉs: sociologie publique, sociologie brésilienne, sociologie critique, sociologues, profession.

Simon Schwartzman - Atualmente é presidente do Instituto de Estudos do Trabalho e Sociedade e membro da Academia Brasileira de Ciências. Foi Presidente da Fundação Instituto Brasileiro de Geografia e Estatística - IBGE (1994-1998). É Doutor em Ciências Políticas pela University of Califórnia, Berkeley (1969). Foi professor do IUPERJ - Instituto Universitário de Pesquisas do Rio de Janeiro (1970-1986). Ocupou a Cátedra Joaquim Nabuco de Estudos Brasileiros na Stanford of University (2001) e foi pesquisador visitante em inúmeros centros, nos Estados Unidos e em países da Europa. Tem experiência na área de Ciência Política, com ênfase em políticas sociais e em estudos sobre o ensino superior. É autor de inúmeros livros, destacandose mais recentemente: Os desafios da educação no Brasil, em co-edição com Colin Brock, (Rio de Janeiro, Nova Fronteira, 2005) e Pobreza, Exclusão Social e modernidade (São Paulo: Augurium Edt., 2004). 